\title{
Evaluación de la Variable Género: CFNI en Mujeres Chilenas
}

\author{
Assessment of the Gender Variable: CFNI in Chilean Women
}

\author{
Raquel Rivas-Diez ${ }^{1}$, Andreea C. Brabete ${ }^{2}$ y María del Pilar Sánchez-López ${ }^{3}$
}

\section{Resumen}

El objetivo de este estudio fue analizar la estructura factorial y la consistencia interna de las puntuaciones del Inventario de Conformidad con las Normas de Género Femeninas (CFNI) en mujeres chilenas. La investigación se llevó a cabo con 308 mujeres, entre 18 y 50 años de edad. El análisis factorial reveló un perfil similar al obtenido en EEUU, por lo que es compatible con la estructura propuesta por los autores. Teniendo en cuenta estos resultados, se concluyó que el CFNI es una buena operativización de la variable género y podrá ser utilizado en futuras investigaciones con mujeres chilenas.

Palabras clave: rol de género, feminidad, fiabilidad, análisis factorial exploratorio

\begin{abstract}
The aim of this study was to analyze the factor structure and the internal consistency of the Conformity to Feminine Gender Norms Inventory - CFNI in the Chilean women. The research was conducted with 308 women between 18 and 50 years of age. Factor analysis revealed a similar profile to that obtained in the USA, it supports the structure proposed by the authors. Taking these results into account, we concluded that the CFNI is a good operationalization of the variable gender and it can be applied to Chilean women in future studies.
\end{abstract}

Keywords: gender roles, femininity, reliability, exploratory factor analysis

\footnotetext{
${ }^{1}$ Doctora en Psicología. Profesora Doctora, Universidad Internacional de La Rioja. C/Milicias 16, 1-A CP. 26003, Logroño, La Rioja, España. Tel: +34616171645. Correo: raquel.rivas@unir.net

2 Doctora en Psicología. Investigadora Postdoctoral, Université de Montréal. 3130 Edouard Montpetit, H3T 1K1, Montreal, Canadá. Tel.: +15416218601. Correo: andreea.catalina.brabete@umontreal.ca

${ }^{3}$ Doctora en Psicología. Profesora Catedrática, Universidad Complutense de Madrid. Escosura, 9. Pozuelo de Alarcón, 28224, Madrid, España. Tel.: +34616981156. Correo: mpsanche@psi.ucm.es
} 


\section{Introducción}

Numerosas investigaciones recientes (Brabete, Sánchez-López, Dresch, Cuéllar-Flores, \& RivasDiez, 2013; Cala-Carrillo \& Barberá-Heredia, 2009; Guo, Han, Zhang, Dang, \& Chen, 2015; Mahalik, Burns, \& Syzdek, 2007; Mahalik, Morray, Coonerty-Femiano, Ludlow, Slattery, \& Smiler, 2005; Woo \& Oei, 2006) han puesto de manifiesto la necesidad de introducir el concepto de género en los estudios psicológicos y de la salud. Recientemente se ha desarrollado una herramienta específica para realizar búsquedas especializadas sobre el sexo y el género en PubMed con el objetivo de transferir a la práctica clínica los conocimientos adquiridos para que mujeres y hombres se vean beneficiados en el proceso de toma de decisiones clínicas (Song, Simonsen, Wilson, \& Jenkins, 2016). La introducción del género como variable en la evaluación de las personas permite avanzar en el esclarecimiento de las relaciones entre el sexo y el género, y aclarar el posible efecto diferencial de ambas sobre otras variables de interés psicológico o social (Colodro-Conde, Limiñana-Gras, \& Ordoñana, 2014; Cuéllar-Flores, Sánchez-López, \& Dresch, 2011; Rivas-Diez, 2011).

Sabemos que las diferentes formas de enfermar en hombres y en mujeres no se explican sólo por diferencias genéticas, con base biológica, y tradicionalmente atribuibles a las diferencias sexuales. Por ello, es necesario introducir el concepto de género para explicar algunas diferencias encontradas que dependen de nuestra forma de vida, de nuestras expectativas, y de otras cuestiones sociales y culturales. Estas últimas se conocen como diferencias de género. Las diferencias de género se han encontrado en diversos comportamientos, en concreto, en los comportamientos relacionados con la salud (Evans \& Steptoe, 2002).

El constructo de Feminidad/Masculinidad ha sido concebido a partir de los trabajos de Bem (1974) como un constructo bipolar cercano al concepto de androginia. El Inventario de Conformidad con las Normas de Género Femeninas (CFNI) de Mahalik et al. (2005) (y su compañero, el CMNI-Inventario de Conformidad con las Normas de Género Masculinas, Mahalik, Locke, Ludlow, Diemer, Scott, \& Gottfried, 2003) se fundamenta en las críticas que se vienen haciendo hacia las medidas clásicas de Feminidad/Masculinidad de los años 70 (Bem, 1974; Berzins, Welling, \& Wetter, 1978; Spencer \& Helmreich, 1974). Las investigaciones más recientes ponen en cuestión ciertos aspectos de este tipo de medidas puesto que los instrumentos elaborados no evaluaban los papeles sexuales en sí mismos sino más bien rasgos de personalidad instrumentales y expresivos (Auster \& Ohm, 2000; Woodhill \& Samuels, 2003). Por ello, el CFNI (Mahalik et al., 2005) supuso una visión renovada del concepto de Feminidad y la incorporación de algunas aportaciones de la psicología social y la investigación actual. El modelo que subyace a este inventario se basa en el concepto de norma social. Las normas de género se consideran un tipo especial de norma social que se define como un conjunto de reglas que guían y prescriben lo que los hombres y las mujeres deben hacer, pensar o sentir (Mahalik, 2000). La feminidad se entiende entonces como el grado de conformidad con un conjunto heterogéneo de normas sociales sobre las conductas, actitudes y creencias que se consideran adecuadas para las mujeres (Mahalik et al., 2005) y que son transmitidas a través de modelos y de agentes sociales.

\section{Construcción del CFNI}

El primer paso en la construcción del instrumento original fue la identificación de las normas femeninas dominantes en la cultura de los EEUU. Los autores revisaron la bibliografía sobre las normas femeninas tradicionales y seleccionaron a 32 mujeres para participar en grupos de discusión. Se les pidió que reflexionaran sobre sus experiencias como mujeres e identificaran los mensajes que habían recibido en cuanto a cómo las mujeres deben pensar, sentir y actuar, así como los beneficios y costos que las mujeres experimentan cuando aprueban o rechazan dichos mensajes. 100 mensajes fueron clasificados en 13 grandes categorías. Finalmente, dos grupos específicos de estudiantes de Máster y Doctorado, formado por hombres y mujeres, se reunieron con el autor principal y discutieron los ejemplos identificados como normas, fueron refinando las categorías y redactando los ítems del cuestionario. Tras el 
análisis factorial, los autores identificaron 8 factores con un total de 87 ítems. Los 8 factores fueron: (1) Valorar agradablemente las relaciones, (2) Cuidadora de niños/as, (3) Delgadez, (4) Fidelidad sexual, (5) Modestia, (6) Romántica en las relaciones, (7) Hogareña e (8) Invertir en la imagen o apariencia (Mahalik et al., 2005).

El CFNI presenta unas características psicométricas satisfactorias en los estudios realizados en EEUU y en su adaptación a la población española. En EEUU, la consistencia interna de las puntuaciones de la escala total es de $\alpha=.88$ y las subescalas obtienen valores de $\alpha=.77 \mathrm{a}$ $\alpha=.92$ (Mahalik et al., 2005). En España, la consistencia interna de las puntuaciones de la escala total es de $\alpha=.87$ y en el caso de las subescalas la fiabilidad de las puntuaciones oscilan entre valores de $\alpha=.64$ a $\alpha=.86$ (SánchezLópez, Cuéllar-Flores, Dresch, \& AparicioGarcía, 2009). Las características del CFNI y del modelo teórico en el que se basa se ajustan a los requisitos de actualización que una medida operativa del género requiere, por ello se procedió a la adaptación chilena del CFNI.

Dado el interés que suscita el género en Chile a nivel social y en temas de investigación (Instituto Nacional de Estadísticas, 2015), y teniendo en cuenta que actualmente no hay ninguna medida para medir este constructo, el objetivo general de este estudio es adaptar el CFNI a las mujeres chilenas. La adaptación de tests no es meramente una cuestión lingüística, sino que exige la conjunción de aspectos culturales, conceptuales, lingüísticos y métricos (Muñiz, Elosua, \& Hambleton, 2013). Las propiedades psicométricas (como por ejemplo fiabilidad y validez) no son características del instrumento sino que son específicas de las puntuaciones obtenidas por el grupo de participantes. Para llevar a cabo dicho propósito se plantean los siguientes objetivos: 1) estudiar la estructura factorial del CFNI en mujeres chilenas para analizar si los factores que definen las normas de género femeninas en mujeres estadounidenses coinciden con los factores que agrupan las normas de género femeninas en mujeres chilenas; 2) calcular los coeficientes de consistencia interna y las correlaciones entre las subescalas del CFNI en las mujeres chilenas; 3) comparar las medias de las normas de género femeninas en mujeres chilenas, españolas y estadounidenses. Se plantean tres hipótesis, una por cada objetivo planteado: 1) el CFNI tendrá una estructura factorial de ocho factores, con buenos índices de ajuste; 2) los coeficientes de consistencia interna de las puntuaciones tendrán valores similares a los encontrados en la población estadounidense y española; la puntuación total del CFNI correlacionará positivamente con cada una de las subescalas del instrumentos; 3) habrá diferencias estadísticamente significativas entre las mujeres chilenas y las mujeres estadounidenses y españolas, respectivamente.

\section{Método}

\section{Participantes}

Participaron 308 mujeres de entre 18 y 50 años, con una media de 32.92 (D.T.=9.37). La mayoría de las mujeres procedían de la capital Santiago de Chile. En general, son mujeres en su mayoría solteras $(48.7 \%)$ o casadas $(33.4 \%)$. El $46.8 \%$ de las mujeres poseían o estaban realizando estudios universitarios y el $45.5 \%$ tenían estudios secundarios. En su mayor parte, pertenecían a un nivel socioeconómico medio-alto $(45.5 \%)$ o medio-bajo (40.6\%). En la Tabla 1 se presentan las características demográficas del grupo de participantes en el estudio.

Tabla 1. Características sociodemográficas de las mujeres chilenas

\begin{tabular}{lc}
\hline$N=308$ & Porcentaje \\
\hline Nivel de estudios & \\
Sin estudios & $.3 \%$ \\
Educación Básica incompleta & $3.2 \%$ \\
Educación Básica completa & $4.2 \%$ \\
Educación Media/Técnico Profesional & $45.5 \%$ \\
Estudios universitarios & $46.8 \%$ \\
Estado civil & \\
Solteras & $48.7 \%$ \\
Casadas & $33.4 \%$ \\
Convive en pareja & $9.4 \%$ \\
En trámites de separación o divorcio & $3.6 \%$ \\
Separada o divorciada & $4.2 \%$ \\
Viuda & $0.6 \%$ \\
Nivel socioeconómico & \\
Bajo & $5.5 \%$ \\
Medio-bajo & $40.6 \%$ \\
Medio-alto & $45.5 \%$ \\
Alto & $8.4 \%$ \\
Edad (Rango 18-50 años) & $D . T$. \\
& \\
&
\end{tabular}


Tabla 2. Descripción de las escalas del CFNI

\begin{tabular}{|c|c|c|c|}
\hline Factor & Subescalas & Descripción & Ejemplos de los ítems \\
\hline 1 & $\begin{array}{c}\text { Valorar } \\
\text { agradablemente las } \\
\text { relaciones }\end{array}$ & $\begin{array}{c}\text { Relaciones de amistad y apoyo a } \\
\text { los demás }\end{array}$ & $\begin{array}{c}\text { Es importante hacer saber a la } \\
\text { gente que son especiales }\end{array}$ \\
\hline 2 & Cuidadora de niños & Cuidar a niños & Cuidaría niños para divertirme \\
\hline 3 & Delgadez & $\begin{array}{l}\text { Perseguir el ideal de cuerpo } \\
\text { delgado }\end{array}$ & $\begin{array}{c}\text { Sería más feliz si fuera más } \\
\text { delgada }\end{array}$ \\
\hline 4 & Fidelidad sexual & $\begin{array}{l}\text { Tener relaciones sexuales dentro } \\
\text { de una relación de compromiso }\end{array}$ & $\begin{array}{l}\text { Sólo tendría sexo si tuviera } \\
\text { una relación de compromiso, } \\
\text { como el matrimonio }\end{array}$ \\
\hline 5 & Modestia & $\begin{array}{l}\text { Evitar llamar la atención sobre } \\
\text { cualidades o talentos }\end{array}$ & $\begin{array}{l}\text { Me siento incómoda si me } \\
\text { escogen para alabarme }\end{array}$ \\
\hline 6 & $\begin{array}{l}\text { Romántica en las } \\
\text { relaciones }\end{array}$ & Cuidar las relaciones amorosas & $\begin{array}{c}\text { Las personas solteras me dan } \\
\text { pena }\end{array}$ \\
\hline 7 & Hogareña & Cuidadora del hogar & $\begin{array}{l}\text { Es importante mantener limpic } \\
\text { el espacio donde se vive }\end{array}$ \\
\hline 8 & $\begin{array}{l}\text { Invertir en la } \\
\text { imagen }\end{array}$ & $\begin{array}{l}\text { Utilizar recursos para mantener } \\
\text { y mejorar la apariencias física }\end{array}$ & $\begin{array}{l}\text { Es importante tener un aspecto } \\
\text { físico atractivo en público }\end{array}$ \\
\hline
\end{tabular}

Fuente: Mahalik et al. (2005)

\section{Instrumento}

Inventario de Conformidad con las Normas de Género Femeninas (CFNI) (Mahalik et al., 2005). CFNI es un inventario de 84 ítems medidos con un formato tipo likert $(0=$ totalmente en desacuerdo, 1 = en desacuerdo, $2=$ de acuerdo y 3 $=$ totalmente de acuerdo). La descripción de las 8 escalas se puede ver en la Tabla 2. El tiempo de aplicación del cuestionario es de 10-15 minutos. Se les pide a las participantes que indiquen el grado en que están personalmente de acuerdo o en desacuerdo con cada afirmación, marcando la respuesta que mejor refleje sus pensamientos, sus propias acciones, sentimientos y creencias.

\section{Procedimiento}

Para la adaptación chilena se tomó como base la traducción y adaptación del CFNI a la población española (Sánchez-López et al., 2009), respetando las normas propuestas por la Comisión Internacional de Tests (International Test Commission, 2001). Para adaptar la variedad idiomática del español que se habla en Chile, cada uno de los cuestionarios se aplicó a un grupo reducido de mujeres chilenas $(N=30)$. Se les pidió que anotasen aquellos ítems y/o palabras que no entendían o que los consideraban inadecuados en su uso lingüístico. Posteriormente, un grupo de personas expertas en género y en lingüística española y las propias autoras de este trabajo analizaron esos ítems e hicieron las modificaciones correspondientes para cada cuestionario. En la versión chilena se há añadido la palabra "corporal" debido a que peso en Chile se utiliza como sinónimo de dinero. Los ítems 71 y 77 han quedado de la siguiente manera en la versión chilena: ítem 71 (Estaría muy contenta conmigo misma aunque ganase peso corporal) e ítem 77 (Ganar peso corporal me da pánico). $\mathrm{Al}$ equipo, formado por cuatro expertos/as, se le pidió que evaluasen cada ítem en términos de adecuación de su contenido, significado, forma y claridad de expresión. El siguiente paso fue volver a aplicar los instrumentos a otro grupo diferente de mujeres $(N=15)$ para contrastar si todavía había discrepancias en el significado o entendimiento de los ítems.

Se procedió a aplicar el instrumento a un grupo de mujeres chilenas. En Santiago de Chile se accedió a la muestra a través de varias Universidades (Universidad Mayor, Universidad Pontificia Católica de Chile), además se proporcionaron instrumentos a varios profesionales de los ámbitos sanitario, educativo y social y se utilizó el método "bola de nieve". La aplicación de los instrumentos se realizó de forma individual mediante autoadministración y, en todos los casos, el instrumento se entregó con una hoja inicial indicando las instrucciones para su aplicación. Todas las participantes del estudio dieron su consentimiento después de que se explicara el propósito de la investigación y la opción de participar, garantizando su libertad para retirarse en cualquier momento del estudio sin ningún tipo de consecuencia. También se garantizó el anonimato de sus datos. En total se 
Tabla 3. Matriz estructural de los ítems del CFNI y carga de los ocho factores. Factorización de ejes principales. Rotación oblimin

\begin{tabular}{|c|c|c|c|}
\hline Factores & Ítems y correspondiente carga (entre paréntesis) & $\begin{array}{r}\text { Varianza } \\
\text { explicada }\end{array}$ & Autovalores \\
\hline Factor 1 & $\begin{array}{l}\text { Ítem } 2 \text { (.511), ítem } 10 \text { (.566), ítem } 19 \text { (-.622), ítem } 27 \text { (-.667), ítem } 36(-.694) \\
\text { ítem } 42 \text { (-.302), ítem } 45(-.499) \text {, ítem } 54(.668) \text {, ítem } 56(-.315) \text {, ítem } 62(.563) \\
\text { ítem } 63(.463) \text {, ítem } 65(.366) \text {, ítem } 67(.300) \text {, ítem } 69(-.356) \text {, ítem } 70(.696) \\
\text { ítem } 75 \text { (-.447), ítem } 76(-.641) \text {, ítem } 80(.699) \text {, ítem } 83(-.646)\end{array}$ & 10.10 & 9.09 \\
\hline Factor 2 & $\begin{array}{l}\text { Ítem } 3(.658) \text {, ítem } 11(-.353) \text {, ítem } 20(.601) \text {, ítem } 28(-.520) \text {, ítem } 37(.653) \\
\text { ítem } 46(.410) \text {, ítem } 55(-.471) \text {, ítem } 60(.308) \text {, ítem } 64(.652) \text {, ítem } 71(-.511) \\
\text { ítem } 77(.598) \text {, ítem } 81(-.304)\end{array}$ & 5.71 & 5.43 \\
\hline Factor 3 & $\begin{array}{l}\text { Ítem } 5(.351) \text {, ítem } 14(-.338) \text {, ítem } 30(-.366) \text {, ítem } 40(.450) \text {, ítem } 43(.383) \\
\text { ítem } 44(.506) \text {, ítem } 48(-.312) \text {, ítem } 49(.443) \text {, ítem } 66(.373), \text { ítem } 75(.308) \\
\text { ítem } 79(.331), \text { ítem } 82(.313)\end{array}$ & 3.84 & 3.87 \\
\hline Factor 4 & $\begin{array}{l}\text { Ítem } 4(-.474) \text {, ítem } 7(-.360) \text {, ítem } 10(-.305) \text {, ítem } 12(.384) \text {, ítem } 15(.386) \\
\text { ítem } 19(.325) \text {, ítem } 21(-.336) \text {, ítem } 29(-.545) \text {, ítem } 32(-.377) \text {, ítem } 39(.494) \\
\text { ítem } 42(.329) \text {, ítem } 47(.547) \text {, ítem } 51(.426) \text {, ítem } 54(-.342) \text {, ítem } \mathbf{5 6}(.541) \text {, } \\
\text { ítem } 62(-.352) \text {, ítem } 65(-.731) \text {, ítem } 68(.346) \text {, ítem } 69(.338) \text {, ítem } 70(-.330) \text {, } \\
\text { ítem } 72(.518) \text {, ítem } 73(.307) \text {, ítem } 76(.358) \text {, ítem } 80(-.344)\end{array}$ & 3.42 & 3.49 \\
\hline Factor 5 & $\begin{array}{l}\text { Ítem } 1 \text { (.431), ítem } 6(.402) \text {, ítem } 18(.368) \text {, ítem } 21(.390) \text {, ítem } 26(-.570) \\
\text { ítem } 30(.380) \text {, ítem } 31(.443) \text {, ítem } 32(.320) \text {, ítem } 33(.429) \text {, ítem } 48(.348) \text {, } \\
\text { ítem } 50 \text { (.598), ítem } 53(.385) \text {, ítem } 63(.456) \text {, ítem } 67(.514) \text {, ítem } 80(.323)\end{array}$ & 3.18 & 3.32 \\
\hline Factor 6 & $\begin{array}{l}\text { Ítem } 7 \text { (-.354), ítem } 8 \text { (-.380), ítem } 16 \text { (-.469), ítem } 32(-.442) \text {, ítem } 34(-.513) \\
\text { ítem } 42(.339) \text {, ítem } 51(.385) \text {, ítem } 52(.442) \text {, ítem } 59(-.348) \text {, ítem } 60(-.404)\end{array}$ & 2.57 & 2.86 \\
\hline Factor 7 & $\begin{array}{l}\text { Îtem } 23 \text { (-.536), ítem } 25 \text { (-.358), ítem } 40 \text { (-.309), ítem } 56 \text { (-.388), ítem } 73 \text { (-.414) } \\
\text { ítem } 84 \text { (-.324) }\end{array}$ & 1.86 & 2.24 \\
\hline Factor 8 & $\begin{array}{l}\text { Ítem } 1 \text { (.351), ítem } 9 \text { (-.394), ítem } 18 \text { (.324), ítem } 21 \text { (.358), ítem } 30(.387) \\
\text { ítem } 41(.413) \text {, ítem } 48(.406) \text {, ítem } 57(.302) \text {, ítem } 58(.397) \text {, ítem } 74(.338)\end{array}$ & 1.66 & 2.08 \\
\hline
\end{tabular}

Nota. Los ítems que se cargan en los factores originales del instrumento en la población de EE.UU se muestran en negrita

entregaron 550 cuestionarios y fueron devueltos 400. De estos 400 cuestionarios, 20 fueron descartados por no haber completado totalmente el instrumento y 72 participantes no fueron incluidas en los análisis debido a que tenían más de 50 años.

\section{Resultados}

\section{Análisis Factorial}

Los valores de medida de adecuación muestral de Kaiser-Meyer-Olkin $(\mathrm{KMO}=.743)$ y la prueba de esfericidad de Bartlett (9875.88, $p<.000$ ) indican que el análisis factorial exploratorio es pertinente utilizando los datos de las mujeres chilenas. Con el objetivo de verificar la estructura subyacente del inventario, se realizó un análisis factorial (ejes principales) con rotación oblicua (oblimin), especificando el número de factores en ocho. El tipo de análisis factorial empleado es el mismo que utilizaron los autores del inventario en población estadounidense (Mahalik et al., 2005).

En el grupo de chilenas, la estructura de ocho factores explica el $32.34 \%$ de la varianza de los ítems, frente al $39.51 \%$ explicado por el mismo cuestionario en el grupo de EEUU (Mahalik et al., 2005). La matriz estructural se muestra en la
Tabla 3, en la que las cargas factoriales inferiores a .30 se han eliminado, un punto de corte razonable para la muestra del estudio $(N=308)$. Los ítems que se cargan en los factores originales del instrumento en la población de EE.UU se muestran en negrita. El Factor 1 explica el mayor porcentaje de varianza (10.10\%), los ítems que tienen cargas factoriales mayores corresponden a la escala Cuidadora de niños del cuestionario original (12 ítems de los 12 que componen la subescala). El Factor 2 explica el 5.71\% de la varianza, los ítems corresponden a la escala Delgadez (11 ítems de los 11 que componen la subescala). En el Factor 3 (3.84\% de la varianza), los ítems corresponden a Modestia (6 ítems de 9). En el Factor 4 (3.42\%), los ítems corresponden a Fidelidad Sexual (9 de los 10 ítems que componen la subescala). La escala Valorar agradablemente las relaciones del instrumento se corresponde con el Factor 5 y saturan 7 ítems de los 18 que componen esta subescala. En el Factor 6 saturan 6 de los 8 ítems de la escala original Hogareña. El Factor 7 se corresponde con la escala Invertir en la imagen o apariencia (satura 1 ítem de 7 ítems). Por último, el Factor 8 corresponde a la escala original Romántica en las relaciones (3 de 9). 
Tabla 4. Correlaciones entre las subescalas del CFNI en la muestra chilena y coeficientes alfa en Chile, EEUU y España

\begin{tabular}{|c|c|c|c|c|c|c|c|c|c|c|c|}
\hline & 1 & 2 & 3 & 4 & 5 & 6 & 7 & 8 & $\alpha$ Chile & $\begin{array}{c}\alpha \\
\text { EEUU }\end{array}$ & $\begin{array}{c}\alpha \\
\text { España }\end{array}$ \\
\hline 1 & 1 & & & & & & & & .71 & .84 & .73 \\
\hline 2 & $.416^{* *}$ & 1 & & & & & & & .89 & .92 & .86 \\
\hline 3 & -.012 & -.095 & 1 & & & & & & .81 & .90 & .80 \\
\hline 4 & $.163^{* *}$ & $.338 * *$ & -.104 & 1 & & & & & .77 & .85 & .80 \\
\hline 5 & $-.241 * *$ & .070 & -.073 & $.225^{* *} *$ & 1 & & & & .63 & .82 & .65 \\
\hline 6 & $.216^{* *}$ & $.155^{* *}$ & .106 & .081 & -.105 & 1 & & & .52 & .77 & .64 \\
\hline 7 & $.265^{* *}$ & $.295 * *$ & -.017 & $374 * *$ & -.105 & $.205^{* *}$ & 1 & & .72 & .84 & .75 \\
\hline 8 & $.132 *$ & .039 & $.262 * *$ & -.052 & $-.219 * *$ & $.235 * *$ & $.257 * *$ & 1 & .68 & .82 & .68 \\
\hline Total & $.588 * *$ & $.686 * *$ & $.311 * *$ & $.557 * *$ & .105 & $.433 * *$ & $.573 * *$ & $.380 * *$ & .83 & .88 & .87 \\
\hline
\end{tabular}

Nota .1 = Valorar agradablemente las relaciones, $2=$ Cuidadora de niños, $3=$ Delgadez, $4=$ Fidelidad sexual, 5 $=$ Modestia, $6=$ Romántica en las relaciones, $7=$ Hogareña, $8=$ Invertir en la imagen

$* * p<.01, * .05$

Fuente: Mahalik et al. (2005) y Sánchez-López et al. (2009)

\section{Consistencia interna y correlaciones entre las escalas}

Se calculó la consistencia interna (coeficiente $\alpha$ de Cronbach) de las puntuaciones de la escala total y de cada una de las subescalas para estimar la fiabilidad del instrumento. Para comprobar si se vuelve a confirmar el modelo multidimensional propuesto por los autores (Mahalik et al., 2005) en las mujeres chilenas, se utilizaron correlaciones entre subescalas (coeficiente de Pearson).

En la Tabla 4 se presentan los resultados del grupo de chilenas, estadounidenses y españolas. El coeficiente alfa para las puntuaciones de la escala total es de $.83 \mathrm{y}$ el rango de valores para las subescalas es de .52 a .89 .

En cuanto a las correlaciones entre las escalas, los resultados señalan que todas las escalas correlacionan positiva y significativamente con la puntuación total. También existen correlaciones entre algunas de las subescalas como se puede ver en la Tabla 4.

\section{Conformidad con las normas femeninas en chilenas, estadounidenses y españolas}

En la Tabla 5 se presentan las medias y desviaciones típicas de las subescalas del CFNI y de la escala total en el grupo de chilenas, estadounidenses y españolas. En la misma tabla aparecen los resultados de las diferencias de medias (prueba $t$ de Student) entre el grupo de chilenas y estadounidenses, y entre el grupo de chilenas y españolas. Los datos de las mujeres estadounidenses y españolas fueron recogidos de los estudios de Mahalik et al. (2005) y SánchezLópez et al. (2009).
Entre el grupo de mujeres chilenas y estadounidenses, los resultados indican que existen diferencias estadísticamente significativas en las subescalas Valorar agradablemente las relaciones, Cuidadora de niños, Delgadez, Romántica en las relaciones, Hogareña, Invertir en la imagen y en la puntuación total. La dirección de las diferencias es de una menor puntuación para las chilenas en las subescalas Valorar agradablemente las relaciones, Cuidadora de niños, Delgadez, Romántica en las relaciones y la escala total; y una mayor puntuación de las mujeres chilenas en las subescalas Hogareña e Invertir en la imagen. Si tenemos en cuenta el tamaño del efecto y las recomendaciones de Cohen (1988), la magnitud de esas diferencias es elevada en Valorar agradablemente las relaciones y Hogareña; moderada en Cuidadora de niños, Delgadez y puntuación total; y baja en Romántica en las relaciones e Invertir en la imagen.

Entre el grupo de mujeres chilenas y españolas, los resultados señalan diferencias estadísticamente significativas en todas las subescalas, excepto Cuidadora de niños y en la puntuación total. La dirección de esas diferencias es de una mayor puntuación para las chilenas en todas las subescalas, excepto en Valorar agradablemente las relaciones y Modestia, en las que la dirección de la diferencia se invierte. El tamaño del efecto es elevado en la subescala Fidelidad sexual; moderado en Delgadez, Hogareña, Invertir en la imagen y la puntuación total; y bajo en Valorar agradablemente las relaciones, Modestia y Romántica en las relaciones. 
Tabla 5. Medias, desviaciones típicas y diferencias de medias entre las escalas del CFNI en Chile, EEUU y

\begin{tabular}{|c|c|c|c|c|c|c|c|}
\hline \multicolumn{8}{|c|}{ España } \\
\hline & $\begin{array}{c}\text { Chile } \\
(N=308)\end{array}$ & EEUU & España & $t$ & & $t$ & \\
\hline & $\frac{(N=308)}{\operatorname{Media}(D . T .)}$ & $\frac{(N=733)}{\operatorname{Media}(D . T .)}$ & $\frac{(N=780)}{\text { Media }(D . T .)}$ & $\begin{array}{l}\text { Chile } \\
\text { EEUU }\end{array}$ & $d$ & $\begin{array}{c}\text { Chile } \\
\text { España }\end{array}$ & $d$ \\
\hline 1 & $35.05(5.75)$ & $39.48(5.97)$ & $36.15(6.30)$ & $11.05^{* *}$ & $\begin{array}{c}.76 \\
\text { (alto) }\end{array}$ & $2.66^{*}$ & $\begin{array}{c}.18 \\
\text { (bajo) }\end{array}$ \\
\hline 2 & $22.72(6.90)$ & $26.51(6.24)$ & $21.84(6.57)$ & $8.66 * *$ & $\begin{array}{c}.58 \\
\text { (medio) }\end{array}$ & 1.96 & \\
\hline 3 & $18.00(5.97)$ & 20.87 (6.18) & $15.18(5.44)$ & $6.91 * *$ & $\begin{array}{c}.47 \\
\text { (medio) }\end{array}$ & $7.49^{* *}$ & $\begin{array}{c}.49 \\
\text { (medio) }\end{array}$ \\
\hline 4 & $19.96(5.17)$ & $20.22(5.55)$ & 16.03 & 0.70 & & $10.87^{* *}$ & $\begin{array}{c}.80 \\
\text { (alto) }\end{array}$ \\
\hline 5 & $12.54(3.63)$ & $13.02(3.67)$ & $13.16(3.38)$ & 1.93 & & $2.67 *$ & $\begin{array}{l}.18 \\
\text { (bajo) }\end{array}$ \\
\hline 6 & $14.47(3.27)$ & $15.64(3.73)$ & $13.72(3.48)$ & $4.79 * *$ & $\begin{array}{c}.33 \\
\text { (bajo) }\end{array}$ & $3.26^{*}$ & $\begin{array}{c}0.22 \\
\text { (bajo) }\end{array}$ \\
\hline 7 & $18.27(3.83)$ & $14.10(3.10)$ & $16.05(4.01)$ & $18.42 * *$ & $\begin{array}{l}1.20 \\
\text { (alto) }\end{array}$ & $8.33^{* *}$ & $\begin{array}{c}.57 \\
\text { (medio) }\end{array}$ \\
\hline 8 & $12.96(3.64)$ & $12.01(3.75)$ & $11.09(3.40)$ & $3.76^{* *}$ & $\begin{array}{c}0.26 \\
\text { (bajo) }\end{array}$ & $8.00^{* *}$ & $\begin{array}{c}.53 \\
\text { (medio) }\end{array}$ \\
\hline $\mathrm{T}$ & $153.97(18.22)$ & $162.73(18.26)$ & $143.22(20.51)$ & $7.07 * *$ & $\begin{array}{c}.48 \\
\text { (medio) }\end{array}$ & $8.03 * *$ & $\begin{array}{c}.55 \\
\text { (medio) }\end{array}$ \\
\hline
\end{tabular}

Nota. 1 = Valorar agradablemente las relaciones, $2=$ Cuidadora de niños, $3=$ Delgadez, $4=$ Fidelidad sexual, 5 $=$ Modestia, $6=$ Romántica en las relaciones, $7=$ Hogareña, $8=$ Invertir en la imagen, $\mathrm{T}=$ Total. $d=$ Tamaño del efecto $* p<.01 ; * * p<.001$

Fuente: Mahalik et al. (2005) y Sánchez-López et al. (2009)

\section{Discusión}

Los resultados del análisis factorial señalan una estructura factorial en los datos chilenos similar a la encontrada en el grupo estadounidense, aunque con variaciones. Aunque Mahalik et al. (2005) seleccionaron los ítems cuyos factores tienen valores iguales o superiores a 0.40 , en este trabajo se consideró que una carga igual o superior a .30 era adecuada para el tamaño de la muestra estudiado (García-Jiménez, GilFlores, \& Rodríguez-Gómez, 2000). Los resultados indican que los factores de la escala Fidelidad sexual (Factor 4) corresponden a la mayor parte de los ítems de los factores extraídos del grupo original estadounidense. Sin embargo, existe diferencia entre la estructura original y la obtenida en la mayoría de los factores. Los ítems que en el grupo de EEUU corresponden a la escala Valorar agradablemente las relaciones (Factor 1) corresponden al Factor 5 del grupo de mujeres chilenas; con los Factores 2, 3, 5, 6, 7 y 8 de la muestra estadounidense (Cuidadora de niños, Delgadez, Modestia, Romántica en las relaciones, Hogareña e Invertir en la imagen) ocurre lo mismo, corresponden a los Factores 1, 2, 3, 8,6 y 7, respectivamente, de la muestra chilena.
Los autores afirman que, teniendo en cuenta que la feminidad es una construcción cultural que varía en función de las características de las personas, incluyendo la edad, es importante examinar los diferentes grupos de mujeres con diferentes características demográficas. En este trabajo, siguiendo las recomendaciones de los autores (Mahalik et al., 2005), incluimos un grupo de participantes de diversas características, no solamente estudiantes universitarias jóvenes.

Los análisis de fiabilidad de las puntuaciones obtenidas en esta muestra indican valores alfa de Cronbach aceptables en la mayoría de las subescalas y en la escala total, por lo que se puede afirmar que las puntuaciones son internamente consistentes. Aunque sus valores son inferiores a los obtenidos en el grupo de estadounidenses, se pueden considerar adecuados. Las puntuaciones que obtienen el menor valor de consistencia interna pertenecen a la subescala Romántica en las relaciones (.52), seguida por la escala Modestia (.63). Estos valores son similares a los encontrados en la adaptación del instrumento a la población española (Sánchez-López et al., 2009).

Las correlaciones entre las subescalas en el grupo de chilenas confirman, de nuevo, el modelo propuesto por el autor (Mahalik, 2000) y 
reproducen con relativa similitud los datos obtenidos por Mahalik en cuanto a la relativa independencia entre las normas de género evaluadas (Mahalik et al., 2003). Las correlaciones significativas entre todas las subescalas con respecto a la puntuación total del CFNI indican que la feminidad (entendida como el grado de conformidad con las normas de género femeninas) es un índice multidimensional, formado por varios mensajes normativos que mantienen relativa autonomía.

La comparación entre el grupo de mujeres chilenas y el grupo de estadounidenses y españolas indica que existen diferencias en la conformidad con las normas femeninas evaluadas. Por un lado, las chilenas en comparación con las estadounidenses presentan una mayor conformidad con las normas de género relacionadas con Hogareña e Invertir en la imagen. La magnitud de esas diferencias es alta en la primera escala y baja en la segunda. Las chilenas tienen una menor conformidad con las normas relativas a Valorar agradablemente las relaciones, Cuidadora de niños, Delgadez y Romántica en las relaciones. Es probable que las diferencias encontradas tengan relación con factores culturales (Ferrer, Bosch, Navarro, Ramis, \& García, 2008). Por otro lado, las chilenas en comparación con las españolas presentan una mayor conformidad con las normas de género relacionadas con Cuidadora de niños, Delgadez, Fidelidad sexual, Romántica en las relaciones, Hogareña e Invertir en la apariencia. La magnitud de las diferencias es elevada en Fidelidad sexual y medio en el resto de las diferencias encontradas. Las chilenas presentan una menor conformidad con las normas relativas a Valorar agradablemente las relaciones y Modestia, aunque la magnitud de esas diferencias en baja.

Los resultados obtenidos demuestran que el CFNI es un inventario adecuado para la población chilena $\mathrm{y}$, teniendo en cuenta el interés que origina el género en Chile, este instrumento es una medida operativa de esta variable. La matriz factorial, la consistencia interna de las puntuaciones y las correlaciones entre subescalas confirman, en general, la estructura propuesta por los autores del instrumento.

El presente estudio presenta una serie de limitaciones. En primer lugar, no puede considerarse que el grupo de mujeres sea totalmente representativo de la población chilena, ya que tan solo participaron 308 mujeres. Cabe destacar que el método de muestreo utilizado "bola de nieve" proporciona igualmente muestras no representativas, por lo que nuestro objetivo no puede cubrirse en su totalidad con este grupo de participantes.

Los resultados presentados deberán replicarse y se deberán revisar las subescalas con menor consistencia interna (Modestia y Romántica en las relaciones). En caso de que se volvieran a encontrar valores pequeños, sería interesante reagrupar ítems en subescalas diferentes y agrupar los ítems en una subescala que incorpore todos los elementos de las escalas relacionadas.

\section{Referencias}

Auster, C. J., \& Ohm, S. C. (2000). Masculinity and femininity in contemporary American society: A reevaluation using the Bem SexRole Inventory. Sex-Roles, 43(7/8), 499-528. doi.org/10.1023/A:1007119516728

Brabete, A., Sánchez-López, M. P., Dresch, V., Cuéllar-Flores, I., \& Rivas-Diez, R. (2013). Gender issues implications on health. En Health Behavior: New Research (pp. 81-102). New York: Nova Publishers (Ed. Peter B. Harris).

Bem, S. (1974). The measurement of psychological androgyny. Journal of Consulting and Clinical Psychology, 42(2), 155-162. doi.org/10.1037/h0036215

Berzins, J. I., Welling, M. A., \& Wetter, R. E. (1978). A new measurement of psychological androgyny based on the Personality Research Form. Journal of Consulting and Clinical Psychology, 46(1), 126-138. doi.org/10.1037/0022-006X.46.1.126

Cala-Carrillo, M. J., \& Barberá-Heredia, E. (2009). Evolución de la perspectiva de género en psicología. Revista Mexicana de Psicología, 26(1), 91-101.

Cohen, J. (1988). Statistical power analysis for the behavioral sciences. Hillsdale, NJ: Lawrence Erlbaum Associates.

Colodro-Conde, L., Limiñana-Gras, R. M. \& Ordoñana, J. R. (2014). Estilos de Personalidad y Adaptación Psicológica en la toma de decisiones sobre lactancia en mujeres 
primíparas. Revista Iberoamericana de Diagnóstico y Evaluación - e Avaliação Psicológica, 2(38), 155-179.

Cuéllar-Flores, I., Sánchez-López, M. P., \& Dresch (2011). El Inventario de Conformidad con las Normas de Género Masculinas (CMNI) en la población española. Anales de Psicología, 27(1), 170-178.

Evans, O., \& Steptoe, A. (2002). The contribution of gender-role orientation, work factor and home stressors to psychological well-being and sickness absence in male and female dominated occupational groups. Social Science and Medicine, 54(4), 481-492. doi.org/10.1016/S0277-9536(01)00044-2

Ferrer, V. A., Bosch, E., Navarro, C., Ramis, C., \& García, M. E. (2008). Los micromachismos o microviolencias en la relación de pareja: Una aproximación empírica. Anales de Psicología, 24(2), 341-352.

García-Jiménez, E., Gil-Flores, J., \& RodríguezGómez, G. (2000). Análisis factorial, Cuadernos de estadística [Factorial analysis. Copybook of Statistics 7]. Madrid: La Muralla.

Guo, X., Han, X., Zhang, X., Dang, Y., \& Chen, C. (2015). Investigating m-health acceptance from a protection motivation theory perspective: Gender and age differences. Telemedicine and e-Health, 21(8), 661-669.

doi.org/10.1089/tmj.2014.0166

International Test Commission (2001). International Guidelines for Test Use, International Journal of Testing, 1(2), 93-114. doi.org/10.1207/S15327574IJT0102_1

Instituto Nacional de Estadísticas (2015). Estadísticas de género. Introducción conceptual. Santiago de Chile: Instituto Nacional de Estadísticas.

Mahalik, J. R. (2000). A model of masculine gender role conformity (Symposium: Masculine gender role conformity: Examining theory, research, and practice). Paper presented at the 108th Annual Convention of the American Psychological Association, Washington DC.

Mahalik, J. R., Burns, S. H., \& Syzdek, M. (2007). Masculinity and perceived normative health behaviors as predictors of men's health behaviors. Social Science and Medicine, 64(11),
2201-2209.

doi.org/10.1016/j.socscimed.2007.02.035

Mahalik, J. R., Locke, B., Ludlow, L., Diemer, M., Scott, R. P. J., \& Gottfried, M. (2003). Development of the Conformity to Masculine Norms Inventory. Psychology of Men and Masculinity, 4(2), 3-25. doi.org/10.1037/1524-9220.4.1.3

Mahalik, J. R., Morray, E. B., Coonerty-Femiano, A., Ludlow, L. H., Slattery, S. M., \& Smiler, A. (2005). Development of the Conformity to Feminine Norms Inventory. Sex Roles, 52(7), 417-435. doi.org/10.1007/s11199-005-3709-7

Muñiz, J., Elosua, P., \& Hambleton, R. (2013). Directrices para la traducción y adaptación de los tests: segunda edición. Psicothema, 25(2), 151-157. doi.10.7334/psicothema2013.24

Rivas-Diez, R. (2011). Inventario de Estilos de Personalidad de Millon (MIPS) en mujeres chilenas. Revista Iberoamericana de Diagnóstico y Evaluación - e Avaliação Psicológica, 31(1), 177-191.

Sánchez-López, M. P., Cuéllar-Flores, I., Dresch, V., \& Aparicio-García (2009). Conformity to feminine norms in Spanish population. Social Behavior and Personality, 37(9), 1171-1186. doi.org/10.2224/sbp.2009.37.9.1171

Spence, J. T., \& Helmreich, R. L. (1974). The Personal Attributes Questionnaire: A measure of sex roles stereotypes and masculinityfemininity. Journal of Personality and Social Psychology, 64(4), 624-635. doi.org/10.1037/0022-3514.64.4.624

Song, M. M., Simonsen, C. K., Wilson, J. D., \& Jenkins, M. R. (2016). Development of a PubMed based search tool for identifying sex and gender specific health literature. Journal of Women's Health, 25(2), 181-187. doi.org/10.1089/jwh.2015.5217

Woo, M., \& Oei, T. (2006). The MMPI2 GenderMasculine and Gender-Feminine scales: Gender roles as predictors of psychological health in clinical patients. International Journal of Psychology, 41(5), 413-422. doi.org/10.1080/00207590500412185

Woodhill, B. M., \& Samuels, C. A. (2003). Positive and negative androgyny and their relationship with psychological health and well-being. Sex Roles, 48(11), 555-565. doi.org/10.1023/A:1023531530272 